\title{
ARTE,TÉCNICA E POLÍtICA NA TRAJETÓRIA DE FRANCISCO PRESTES MAIA
}

\section{Marisa Varanda Teixeira Carpintéro}

\section{Resumo}

Proponho neste artigo explorar as múltiplas linguagens que norteiam as formas do pensamento político do ex-prefeito da cidade de São Paulo o eng-arquiteto Francisco Prestes Maia.Como urbanista e como homem público Prestes Maia ao longo de sua trajetória se preocupou em construir a sua imagem na esfera pública como técnico, mostrando-se capaz de solucionar os problemas da cidade e ainda como o político honesto "avesso a política e aos políticos partidários". Nesse percurso recupero seus desenhos, planos urbanísticos, relatórios de prefeito, artigos escritos para revistas especializadas, em jornais, comícios, programas de governo e nas propagandas como candidato a prefeito, com o intuito de desvendar os limites, conflitos e os paradoxos de sua trajetória como urbanista e político. Ainda destaco alguns aspectos que demarcaram a relação dos conceitos políticos e filosóficos do urbanismo com a política do Estado Novo e seus desdobramentos na década de 1960.

\section{Palavras chaves}

arte, técnica, política, urbanismo.

\section{Abstract}

In this paper I propose to exploit the multiple languages that had an influence over the political thought of the ex-mayor of São Paulo city, the engineer and architect Franciso Prestes Maia. Both as an urbanist and as a public figure, Prestes Maia was concerned, through his trajectory, with the construction of his public image as a technician, someone able to solve the city problems, and as well as a honest politician " contrarious to the politics and the parties politicians". Intended to unveil the limits, conflicts and paradoxes of his trajectory as an urbanist and politician, I recover and review his drawings, urban plans, mayor reports, articles written for scientific magazines and newspapers, speeches, government programs, and the material of his campaign for mayor election. At least, I emphasize some aspects that have marked the relation between the political and philosophical concepts of the urbanism as a policy of the "Estado Novo" and it is unfolding in the decade of 1960.

\section{Keywords}

art , technique, policy, urbanism 


\section{Introdução}

Prestes Maia, homem de reconhecida competência e honestidade. Paulista, ilustre, administrador experimentado, urbanista insígne. Engenheiro de notável capacidade de trabalho, acima de quaisquer influências partidárias, de energia comprovada em longos anos de atividade pública e particular, inatacável nos seus atos, conhecedor como ninguém de todos os problemas municipais, é o homem indicado para dar a cidade de São Paulo, orgulho de nossa gente, administração que merece e que necessita.(Folheto de Campanha para a prefeitura de São Paulo de Francisco Prestes Maia)

Com essas palavras o folheto da campanha a prefeitura de São Paulo, no ano de 1961, anunciava as principais características do candidato Engenheiro-arquiteto Francisco Prestes Maia.Como urbanista e como homem público Prestes Maia ao longo de sua trajetória se preocupou em construir a sua imagem na esfera pública mostrando-se "avesso a política e aos políticos partidários e também como "técnico honesto"e capaz de solucionar os problemas urbanos". Cabe destacar que foi prefeito interventor de 1938-1945, ainda candidato, em 1953 a governador de São Paulo, em 1957 à prefeitura de São Paulo se elegendo, entretanto, a prefeito de São Paulo (1961-1965). Proponho neste artigo investigar as múltiplas linguagens que norteiam as formas do pensamento político de Prestes Maia expressas em seus desenhos, planos urbanísticos, relatórios de prefeito, artigos escritos para revistas especializadas, em jornais, comícios, programas de governo e nas propagandas como candidato a prefeito, com o intuito de desvendar a relação entre o saber urbanístico e a dimensão afetiva da vida política ${ }^{1}$.

Neste texto procuro trazer Prestes Maia para seu tempo e lugar ${ }^{2}$, e me encontrar com a imagem que ele próprio construiu no decorrer da sua carreira ou segundo outros que com ele conviveram ou sobre ele escreveram. Contudo acompanhar a trajetória política desse urbanista exige cuidados e assim como nas recomendações apontadas pela historiadora Vavy Pachecco Borges em seu artigo " O eu e o outro na Relação Biográfica ", devemos nos atentar para a importância em

\footnotetext{
${ }^{1}$ Consultar o artigo Marisa Carpintéro ,"Linguagens políticas na trajetória do engenheiro-arquiteto Francisco Prestes Maia" publicado no livro org. SEIXAS,Jacy,CERASOLI,Josianne e NAXARA, Márcia, Tramas do Político :Linguagens, Formas,Jogos, Urbelândia,EDUFU, 2012. Importante os estudos de Ansart, Pierre, "La gestion des passions politiques, L' Age d' Homme, Lausanne,1998.

2 A "Biblioteca Municipal Francisco Prestes Maia", antiga "Biblioteca Municipal Presidente Kennedy" (até 1996), localizada no Distrito de Santo Amaro na cidade de São Paulo.

URBANA, V.5, n 7, out.2013 - Dossiê: Urbanistas e Urbanismo: a escrita da história... - CIEC/UNICAMP
} 
como escrever uma biografia. Essa historiadora além de apresentar uma série de estudos que trataram de discutir as relações entre o biógrafo com o seu biografado, nos oferece essa preciosa lente para se olhar o outro, ao esclarecer que:

a partir de que circunstâncias sabemos que somos fragmentados, contraditórios e que mudamos nossos comportamentos ao longo do tempo, mas permanecemos de algum modo também os mesmos e que apresentamos diferentes imagens para diferentes pessoas ou para nós mesmos em diferentes momentos. Como nós nossos personagens históricos não são modelos de coerência, de continuidade, de racionalidade, como para nós, as tensões entre o vivido e o que foi imaginado e desejado são fundamentais em suas vidas. (BORGES,2009,P.233)

Os cuidados apontados por Vavy Pachecco Borges, com relação à busca de coerências nos ajuda entender, as facetas de técnico e político, assim como dos interlocutores de Prestes Maia. Esses cuidados são necessários, principalmente quando se trata de uma figura com uma trajetória repleta de atuações em diferentes campos profissionais. Concordamos com o historiador Eric Hobsbawn, quando diz que:

o acontecimento, o indivíduo, e mesmo a reconstrução de algum estado de espírito, o modo de pensar o passado, não são fins em si mesmos, mas constituem o meio de esclarecer alguma questão mais abrangente, que vai muito além da estória particular e seus personagens. (HOBSBAWN, 1991,PP.39-46)

Da mesma forma o filósofo Pierre Bordieu, alerta seus leitores para a noção de trajetórias, dizendo que:

tentar compreender uma vida como uma série única e, por si só, suficiente de acontecimentos sucessivos, sem outra ligação que a vinculação a um " sujeito" cuja única constância é a do nome próprio, é quase tão absurdo quanto tentar explicar um trajeto no metrô sem levar em conta a estrutura da rede, isto é, a matriz das relações objetivas entre as diversas estações.(BORDIEU,1996,p.81) 
Para Bordieu os acontecimentos biográficos definem-se antes como alocações e como deslocamentos no espaço social, isto é, nos diferentes tipos de capital que esta em jogo.

Contudo, os estudos desenvolvidos por Bernard Lepetit, com relação as diversas escalas de análise, isto é, do particular aos macrofenômenos também acrescenta outras possibilidades de análise e ainda ajudam a percorrer os caminhos da história a partir das trajetórias e biografias. ${ }^{3}$ (LEPETIT,2001)

Vale à pena mencionar a contribuição do historiador Carlo Ginsburg, em especial o seu livro "O Queijo e o Verme", que também oferece outra forma de conceber a história social, destacando na trajetória de um individuo, de um grupo ou de uma obra , a complexa rede de relações nos quais se inscreve.(GINSBURG,1997) Percorro nesse texto a trajetória de Prestes Maia resgatando as diferentes linguagens que considero importante para a leitura de sua imagem e ainda destaco alguns aspectos que demarcaram a relação dos conceitos políticos e filosóficos do urbanismo com a política do Estado Novo e seus desdobramentos na década de 1960.

\section{Prestes Maia em sua trajetória}

"Nasci em 19 de março de 1896, em Amparo, filho de Manoel de Azevedo Maia e Carolina Pupo Prestes Maia," relata Francisco Prestes Maia em um dos seus testamentos escrito em 1929. A família mudou-se para São Paulo, em 1907, e Francisco Prestes Maia inicia e completa seus estudos de primeiro e segundo graus no Colégio São Bento. Aos 15 anos ingressa na Escola Politécnica no curso de Engenharia e Arquitetura e o conclui em dezembro de 1917. No mesmo ano começa a trabalhar com imóveis e também como engenheiro fiscal do Hospício do Juqueri, assumido, José Vidigal Pontes, sua primeira incursão na administração pública.(PONTES,1996,p.4) Em 1918 foi convidado para trabalhar na comissão preparatória das comemorações do Centenário da Independência, as quais consistiam na criação de conjuntos urbanísticos, abertura da avenida Independência, execução de obras no Museu Paulista, reforma e construção do Monumento do Centenário e canalização do córrego Ipiranga. Ainda na mesma época, São Thiago e Ramos de Azevedo o indicavam para trabalhar junto à Secretaria do Interior sob a direção de Alfredo Braga, diretor das Obras Públicas do Estado. Só em 1926, depois de ter prosseguido nesses trabalhos, integrando na Comissão Construtora da Avenida Independência, ao lado de Mario

\footnotetext{
3 Consultar também Faria, Rodrigo, Biografia, não mais Trajetória: para (re)pensar argumentos de outrora,Posfácio do Livro "O Urbanista e a Cidade, José de Oliveira Reis e o Rio de Janeiro - uma biografia profissional". Editora Alameda/FAPESP,2011

URBANA, V.5, n 7, out.2013 - Dossiê: Urbanistas e Urbanismo: a escrita da história... - CIEC/UNICAMP
} 
Whately, Modesto Costa Ferreira e Antonio Smith Bayma, monta em 1922, o escritório de engenharia e realiza uma série de projetos avulsos, entre eles o Viaduto do Chá e algumas reformas de residências em São Paulo.

Em toda sua vida de estudante, Prestes Maia, seguiu um percurso brilhante: do Colégio São Bento à Escola Politécnica suas notas revelavam a intensidade e o envolvimento com o estudo. Este é o motivo da existência dos 12 mil livros de sua biblioteca particular, que hoje pertence à Biblioteca Municipal Francisco Prestes Maia. Neste acervo podemos encontrar assuntos variados, dentre eles, literatura, história, arquitetura, filosofia, estética, finanças, teatro e política. Além dos livros são muitas as revistas francesas e italianas sobre construção, serralheria e mesmo decoração e tapeçaria, sem contar as enormes prateleiras repletas de relatórios e projetos que foram apresentados para São Paulo e interior.

Conforme sua esposa, Maria de Lourdes Prestes Maia,"...as edições raras eram encomendadas aos livreiros europeus de Florença, Leipzig e outras cidades. Da Europa vinham obras em inglês, francês, alemão, grego(antigo), italiano, latim". (FAERMAN,1996,p.26).Daí a familiaridade com outros idiomas expressos em varias citações de autores ingleses, alemães e franceses, encontradas no Plano de Avenidas. Outra curiosidade é que apesar de não ter tido formação acadêmica em Urbanismo, que como denominação e disciplina era relativamente recente, o mesmo demonstra o contato com as várias correntes urbanísticas da época, através das leituras realizadas, em inglês na sua maioria, abrangendo discussões relativas à engenharia sanitária, hidráulica, irrigação, planejamento urbano, tráfego, transportes, pontes, portos, geologia, e outros.

Como profissional liberal, elaborou planos e projetos urbanísticos foi integrante da Comissão da Reforma Urbanística de Buenos Aires e assumiu a Diretoria da Companhia City. De 1947 a 1950 realizou vários planos urbanísticos para as cidades de Santos, Belo Horizonte, Campos do Jordão, Belo Horizonte, Curitiba, Votuporanga, Ribeirão Preto, Campinas, Poços de Caldas,Recife, Londrina e Santo André, além de esboçar planos para cidades inteiras como Cristo Rei (RJ) e Jardim Umuarama(Go) e a cidade de Panorama.O nome de Prestes Maia ganhou repercussão como urbanista e também na esfera política, em julho de 1930, quando a sua obra Estudo de um Plano de Avenidas para a cidade de São Paulo foi premiada, no IV Congresso Pan- americano, na cidade do Rio de Janeiro. ${ }^{4}$ Cabe esclarecer o alcance

4 No ano de 1914, após a Primeira Guerra, um grupo de arquitetos e várias autoridades políticas do Uruguai, dentre eles presidente da Republica do Uruguai, o arquiteto Dom Alfredo Baldomir, reuniram -se URBANA, V.5, no 7, out.2013 - Dossiê: Urbanistas e Urbanismo: a escrita da história... - CIEC/UNICAMP 
político e acadêmico do Congresso, integrando vários arquitetos reconhecidos e autoridades da Argentina, Chile, Uruguai, Panamá, Venezuela, Cuba, Canadá e Estados Unidos, recepcionados pelo então presidente da República do Brasil Washington Luís Pereira de Sousa, ministro da Justiça Augusto Vianna do Castello e o prefeito do Rio de Janeiro Antonio Prado Júnior.Prestes Maia participa como membro do comitê de organização do IV Panamericano e como representante do governo de São Paulo na cerimônia de encerramento. ${ }^{5}$

Em 1934 - Prestes Maia articula com outros urbanistas, dentre eles Luis de Anhaia Mello, a formação da Sociedade Amigos da Cidade, entidade civil que se propunha a apontar soluções para os problemas da cidade e lutar para a elaboração do Plano Geral da Cidade e pela formação de uma Comissão do Plano da Cidade, sendo o seu primeiro presidente. ${ }^{6} \mathrm{O}$ contato através da Sociedade dos Amigos da Cidade com políticos, profissionais liberais, empresários, artistas e pessoas influentes, bem com a sua participação como júri nos concursos do Palácio do Congresso Estadual (1935), do edifício do Conde Matarazzo no vale do Anhangabaú e mais tarde da cidade universitária (1945), descerravam os caminhos da política associando ao seu

na cidade de Montevidéo, lançando o fundamento de uma associação de classe para a defesa de seus princípios profissionais e também para promover por todo continente sob a forma de Congressos PanAmericanos de Arquitetos.O Primeiro Congresso Panamericano de Arquitetos aconteceu em 1920, na cidade de Montevidéo, o $2^{\circ}$ Congresso Panamericano de Arquitetos (1923 na cidade de Santiago,no Chile), 30 Congresso Panamericano de Arquitetos (1927 na cidade de Buenos Aires - Argentina), 40 (1930 na cidade do Rio de Janeiro-Brasil).Sobre os Panamericanos consultar os estudos de GUTIÉRREZ, Ramon, TARTARINI, Jorge e STAGNO, Rubens, Congresos Panamericanos de Arquitectos 1920- 2000, Buenos Aires;CEDODAL,2007.

5 "El IV Congreso Panamericano de Arquitectos " in Revista de Arquitectura, Buenos Aires, n0116, ano XVI, agosto de 1930 .

${ }^{6}$ Cabe aqui destacar alguns aspectos importantes com relação à atuação da Sociedade Amigos da Cidade na vida política e social da cidade de São Paulo.Primeiramente a presença de reconhecidos nomes da vida artística, política e econômica da cidade, como membros e fundadores da Sociedade: Golfredo da Silva Telles, Luiz de Anhaia Mello, J. Wasth Rodrigues, Antonio Prado Júnior, Dacio A. de Moraes, Roberto Simonsen, Guilherme Dumond Villares, Leo Ribeiro de Moraes, Julio de Mesquita Filho, Victor da Silva Freire, Jorge Americano e outros. Outro aspecto importante é perceber o canal de comunicação entre os integrantes da Sociedade e os programas e ações do poder municipal. Ao percorrer as atas da Sociedade de Amigos da cidade de 1935 a 1945, é possível acompanhar uma série de discussões sobre os problemas que segundo eles, ameaçavam o cotidiano da cidade. As reuniões semanais da Sociedade eram regadas com intensos debates dos projetos a serem implementados na cidade. É o caso do projeto de construção do aeroporto do Ibirapuera que recebeu a manifestação contrária a sua execução. Alguns debates transformavam-se em artigos e eram publicados pela Revista da Sociedade Amigos da Cidade intitulada Amigos da Cidade, entre os artigos publicados, pode-se destacar: O Zoneamento Urbano (1936) escrito por Francisco Prestes Maia, O Transporte Coletivo de São Paulo (1947) memorial enviado ao Conselho Administrativo do Estado de São Paulo, São Paulo Cidade sem Parques e áreas verdes (1950) memorial enviado ao prefeito Municipal de São Paulo Dr. Christiano das Neves. O artigo $13^{\circ}$ do Estatuto da Sociedade apresenta a criação de nove Comissões Technica: 1)Cadastro Urbano, 2)Obras Públicas, 3)Turismo e Propaganda, 4)Legislação e Fazenda,5)Parques e Jardins,6)Hygiene e Saúde Pública,7)Administração Pública, 8)Arte e Instrução Pública,9)Circulação e Transporte.Sendo que cada uma dessas Comissões eram representadas por cinco membros eleitos pelos representantes da Sociedade. Cabe destacar que Francisco Prestes Maia e Luiz de Anhaia Mello, Antonio Prado Junior, Golfredo da Silva Telles, Victor da Silva Freire e Ubaldo Franco Caiuby pertenciam, no ano de 1938, da $1^{\mathrm{a}}$ Comissão de Cadastro Urbano(Plano da Cidade).

URBANA, V.5, n 7, out.2013 - Dossiê: Urbanistas e Urbanismo: a escrita da história... - CIEC/UNICAMP 
nome a capacidade técnica-administrativa. ${ }^{7}$ Em 10 de novembro de 1937, quando Getúlio Vargas decreta uma nova constituição. Era o início do Estado Novo, regime em que os Estados eram administrados por interventores nomeados pelo presidente da República e os prefeitos das capitais eram indicados pelos interventores. Neste quadro político-institucional Prestes Maia é nomeado prefeito de São Paulo pelo interventor Adhemar de Barros. Como já disse no início ele foi ainda candidato, em 1953 a governador de São Paulo, em 1957 à prefeitura de São Paulo se elegendo, entretanto, a prefeito de São Paulo (1961-1965).O fato de ter ocupado o cargo de prefeito da cidade de São Paulo, permitiu a possibilidade de implementar, no decorrer dessas duas gestões, a sua principal obra o "Plano de Avenidas". ${ }^{8}$ Cabe ressaltar que essa obra demarcou toda a sua trajetória como político e urbanista, significou o elemento essencial para todas as suas ações em sua campanha e depois ao longo de sua gestão como prefeito ${ }^{9}$

\section{O urbanismo, os urbanistas e os Planos para São Paulo e Rio de Janeiro}

Para entender a força de convencimento e o alcance político das diversas linguagens presente no Plano de Avenidas, pretendo chamar atenção para a maneira como Prestes Maia e seus contemporâneos, dentre eles o arquiteto francês Alfred

\footnotetext{
${ }^{7}$ Cabe lembrar da participação de Prestes Maia no Primeiro Congresso de Habitação no ano de 1931 na cidade de São Paulo, um evento patrocinado pelo Instituto de Engenharia de São Paulo e Prefeitura Municipal de São Paulo. Nesse mesmo ano foi um dos fundadores do Instituto Paulista de arquitetos permanecendo como vice-presidente de (1930-1931).

8 Maia, Francisco Prestes, Introducção ao Estudo de Um Plano de Avenidas para a cidade de São Paulo,São Paulo,Companhia Melhoramentos de São Paulo, 1930. Esta obra, marcou um percurso importante na história do urbanismo, pois é sabido que poucos urbanistas conseguiram colocar em prática grande parte dos seus projetos urbanísticos. Este estudo representa parte da sua vida, os caminhos que percorreu na sua formação pessoal,além disso, significa as opções feitas em vários momentos como intelectual e político. Este livro foi publicado, em 1930, na época que Prestes Maia ainda era o engenheiro civil e arquiteto da Secretaria de Viação e Obras Públicas de São Paulo.Neste Plano podemos desfrutar toda a erudição e as diferentes formas de linguagens utilizadas por esse urbanista. Reitero que são inúmeras as citações em francês, inglês e alemão de conceituados urbanistas europeus e norte-americanos, ao lado das análises de suas principais obras. Outras linguagens despontam nessa obra através das aquarelas ricas em detalhes ornamentais, ou, na série de fotos antigas da cidade de São Paulo, além dos inúmeros gráficos, plantas e mapas.

9 Já no doutorado me sentia motivada em aprofundar os aspectos que marcaram a trajetória política desse engenheiro-arquiteto, até porque grande parte da literatura, particularmente, os estudos da área de arquitetura e urbanismo se voltaram para as leituras e análises das suas obras.Verificar os trabalhos dos seguintes arquitetos: Maria Cristina da Silva Leme, Revisão do Plano de Avenidas - Um estudo sobre o Planejamento Urbano em São Paulo, 1930, (1990)FAU/USP, Marta Dora Grostein, Acidade clandestina : Os mitos e os ritos (1900-1987), São Paulo, Tese de doutorado,FAU-USP

- Regina Prosperi Meyer,Metrópole e Urbanismo - São Paulo 50, Tese de doutorado, Faculdade de Arquitetura e Urbanismo, FAUUSP, 1991), Raquel Rolnik, A cidade e a Lei - Legislação, política e territórios na cidade de São Paulo, 1997, Studio Nobel,Maria Adélia Aparecida de Souza, A Identidade da Metrópole, Editora Hucitec 1994, Benedito Lima Toledo, Prestes Maia e as origens do principal obra," A Introdução ao Estudo do Plano de Avenidas para a cidade de São Paulo" Urbanismo Moderno, 1996, Sarah Fedman, Planejamento e Zoneamento em São Paulo, 1947-1972, Nadia Somek,. A cidade Vertical e o urbanismo Modernizador - São Paulo 1910-1939, 1997, EDUSP, 2005,.Candido Malta Campos. Os rumos da cidade. Urbanismo e Modernização em São Paulo, São Paulo: SENAC ,2000.
}

URBANA, V.5, no 7, out.2013 - Dossiê: Urbanistas e Urbanismo: a escrita da história... - CIEC/UNICAMP 
Agache, autor do livro Cidade do Rio de Janeiro - Extensão e Embelezamento (1926) se colocavam, diante da sociedade e ainda como eles procuravam definir o urbanismo e qual seria o papel do urbanista. ${ }^{10}$

Inicio esse percurso com o discurso proferido, em 1933, pelo Engenheiro Carlos W. Stevenson na sede do Rotary Club de Campinas.

Esse engenheiro define o "urbanismo "como;

...a ciência ou arte de traçar cidades de coordenar o conjunto de elementos que melhor correspondam, não sómente ás conveniencias de circulação, higiene, conforto, ás facilidades de trabalho e recreio dos seus habitantes, como ainda, aos exigentes preceitos de estética e elegância próprios das cidades modernas. (STEVENSON,1934.p.7)

Ainda esclarece que urbanismo é ciência quando entra na indagação da forma de existência e atividades dos homens em sociedade, para estudar as condições necessárias de habitação, higiene e conforto e quando prevê o desenvolvimento futuro das aglomerações urbanas. Nessa definição de "urbanismo" é possível captar o conceito de cidade, ou seja, para esse engenheiro a cidade é o espaço de civilização. O arquiteto francês Alfred Agache(1926) complementa a definição acima alertando que "...o urbanismo não é sómente uma Arte e uma Ciência, é, antes de tudo, uma filosofia social , pois é fato que o econômico e o social intervêm nitidamente na criação, no desenvolvimento e na evolução da cidade." 11 Ciência de aplicação e conforme as definições acima, apontam a utilidade social do urbanismo e de acordo com os estudos de Catherine Bruant, engloba os elementos sociais que fazem parte da composição das cidades, que determinam seu nascimento, seu crescimento e sua decadência, e uma meta: curar a cidades doente, pois existe uma patologia e uma terapêutica urbanas, assim como uma terapêutica humanas.

É interessante trazer aqui a visão orgânica e mecanicista da cidade e o papel do urbanista presente nos estudos desenvolvidos pelo arquiteto francês Alfred Agache, frente ao "Plano de Remodelação, Extensão e Embelezamento para a cidade

\footnotetext{
${ }^{10}$ Importa lembrar que o arquiteto Donalt Alfred Agache foi uma das figuras essenciais do movimento de institucionalização do urbanismo na França, durante as décadas marcantes do início do Século XX e as que se estendem até a Segunda Guerra Mundial. Jovem diplomado pela École des Beaux-Arts de Paris.

${ }^{11}$ Verificar o artigo de Bruand, Catheriene Donald Alfred Agache:urbanismo, uma sociologia aplicada in Cidade, Povo e Nação Gênese do urbanismo moderno, Org.Ribeiro Luiz Cesar de Queiroz e Pechman Robert, Rio de Janeiro, Civilização Brasileira, 1996, p 174.

URBANA, V.5, n 7, out.2013 - Dossiê: Urbanistas e Urbanismo: a escrita da história... - CIEC/UNICAMP
} 
do Rio de Janeiro ", elaborado no ano de 1926, na administração do prefeito Antonio Prado Júnior .Logo na introdução, o plano Agache procura definir o papel do urbanista como o médico da cidade, isto é, aquele que servirá da técnica para afastar e prevenir os males causados pela crise do crescimento desordenado. Agache faz o seguinte comentário, após uma visita ao Rio de Janeiro:

Mme. Carioca que acabo de visitar,está certamente doente, não temaes, porém, porquanto a sua moléstia não é congênita: é daquellas que são passíveis de cura, pois o seu mal consiste em uma crise de crescimento (AGACHE, 1926,p.5)

Desse modo, Agache aponta o diagnóstico sobre a cidade do Rio de Janeiro e prescreve o medicamento eficaz no combate à patogênese da cidade. $O$ medicamento apresentava em sua substância uma considerável dosagem de progresso e disciplina e ainda acompanhadas de um severo regime preventivo que, na opinião desse urbanista seria, então, a fórmula ideal para desabrochar da cidade carioca. Tal como no organismo humano, cada órgão da cidade possui uma função determinada. No entender dos urbanistas, à proporção que a cidade vai crescendo, as funções vão se diferenciando, ou se desequilibrando, no entanto, elas só funcionarão de forma perfeita se houver equilíbrio e harmonia entre as funções. Ao analisar o discurso organicista de Agache, é possível notar a utilização da história como tentativa de caracterizar a origem da disciplina urbanismo. Em seus livros, "Nos Agglomérations rurales, comment le aménager(1916) e Comment reconstruire nos Cité détruites(1916), ele estuda os burgos e as aldeias destruídas na França, denunciando os aspectos insalubres dessas aglomerações.Já no Plano para o Rio de Janeiro, ele se coloca como médico responsável pelo destino da vida urbana.Para tanto, ele destrói as cidades do passado, constrói a imagem do presente e ainda projeta a do futuro.

A postura acima do arquiteto Alfred Agache em seu Plano de Remodelação para a cidade do Rio de Janeiro nos aproxima do Plano de Avenidas de Prestes Maia. Tais aproximações se dão em vários aspectos: primeiramente lembrar que os dois planos foram elaborados no final de 1920, ambos seguem o mesmo protocolo em sua apresentação, ou seja, os mesmos instrumentos de linguagens, as várias citações de autores e obras estrangeiras, a quantidade de ilustrações como fotos antigas e recentes da cidade, desenhos, mapas, plantas e gráficos. Todavia, a proximidade maior entre eles ocorre na esfera do discurso, isto é, na visão técnica e organicista da cidade. No Plano de Avenidas as terminologias médicas estão presentes como forma de tratamento do corpo urbano, daí o sentido das expressões artérias mestras, rede arterial, circulação, célula urbana, esqueleto, coração e pulmão. Outra semelhança URBANA, V.5, no 7, out.2013 - Dossiê: Urbanistas e Urbanismo: a escrita da história... - CIEC/UNICAMP 
entre os discursos se dá no tocante a positividade na técnica, no caráter preventivo do Plano e na onipotência do urbanista.

Ao iniciar o Plano de Avenidas, Prestes Maia ressalta que os problemas existentes na cidade de São Paulo são os mesmos que ocorrem em grande parte nas cidades modernas: "A maioria das dificuldades presentes são de ordem universal, oriundas de condições peculiares a vida moderna e dellas sofrem todas as grandes cidades." (MAIA,1939p.1)O congestionamento, aglomeração, as habitações insalubres, a inexistência de obras sanitárias, iluminação, água e falta de esgoto são elementos incompatíveis com o desenvolvimento da cidade. Na opinião de Prestes Maia, estes elementos prejudiciais para a vida urbana poderão ser eliminados a partir da aplicação de uma nova doutrina, isto é, da doutrina do urbanismo moderno. Áreas de lazer, grandes avenidas, parkways, melhoramentos em ruas e estradas, pontes, iluminação, abastecimento de água, subway em conjunto com um plano geral, uma legislação estadual, municipal necessária à execução do plano e ao seu financiamento representavam medidas cruciais para os ditames da nova ordem urbana. Todas essas imagens temperadas pela noção de progresso transmitiam confiança aos eleitores e delegavam o poder ao urbanista.

Para ambos a palavra circulação representava um elemento importante dentro das suas propostas urbanísticas, pois ela

...é o reflexo imediato do surto econômico, as avenidas, as ruas, as praças precisam de ser fiscalisadas de tal forma, que não sejam surprehendidas pela intensidade do movimento. Tratemos da congestão, systema mórbido, para a cura da qual o único remédio é o remodelamento, ao menos parcial, das praças e das ruas, e no Rio isso é urgente. (AGACHE,1926,p.6)

As propostas de circulação de Prestes Maia, originam-se dos estudos de Eugéne Hénard, particularmente, no que se refere ao PERÍMETRO DE IRRADIAÇÃO. Estes estudos orientaram Prestes Maia a pensar na expansão da área central da cidade. Ao comparar o três planos feitos pelo urbanista Hénard para as cidades de Berlim, Londres e Moscou, Prestes Maia em parceria com Ulhôa Cintra procura definir o traço comum presente no plano para estas cidades. Desse modo, observa que, todas as vias de expansão e penetração convergem para um núcleo central, mas alerta que nem todas se dirigem para o mesmo ponto. Ao contrário, reforça o autor, todas essas vias,"..se ligam a uma espécie de circuito fechado ou coletor, que nós URBANA, V.5, no 7, out.2013 - Dossiê: Urbanistas e Urbanismo: a escrita da história... - CIEC/UNICAMP 
propomos chamar perímetro de irradiação e que traçado a uma certa distancia do centro mathemático da cidade". (CINTRA,MAIA,1924,p.124) Este perímetro seria o regulador da circulação; é ele que recebe e distribui com o auxílio das pequenas ruas o fluxo de movimento individual de cada elemento da circulação. Como todas as ideias apresentadas no Plano contém uma justificativa centrada no olhar futurístico do urbanista sob o traçado e a história da cidade. Neste caso a escolha feita em torno da proposta de Hénard, se dá pelo seguinte motivo: ao contrário das cidades americanas, São Paulo teve a sorte de não ser presenteada, ao nascer " com o clássico plano em xadrez".

Vejamos então como a história da fundação da cidade é articulada ao discurso técnico calcado nos princípios da circulação:

Assim ela nasceu e cresceu á maneira das velhas cidades europeias. Aconchegou-se, primeiramente, em torno da Igreja jesuítica, acastelando-se, na colina de fundação, em posição magnificamente estratégica contra as tribos selvagens, que a punham em contínuo sobressalto. Desse núcleo, desse centro, que ainda é hoje o coração da cidade, irradiaram-se as primeiras veredas em demanda dos aldeamentos vizinhos. Como em toda parte, essas veredas passaram a estradas e hoje são grandes ruas da nossa cidade. (CINTRA,MAIA, 1924)

O autor procura na leitura do tempo ao lado da configuração do espaço os elementos que naturalmente coincidem com a proposta mais indicada. A história e a topografia também fazem parte da proposta de Agache para a circulação do Rio de Janeiro, embora tenha escolhido, outras alternativas para a definição do sistema viário. (BRUAND,1991,p.335) Todavia a influencia de Hénard se faz presente na obra de Agache ao se referir a importância da circulação:

A prosperidade de uma cidade é resultante dos esforços de seus habitantes em todos os ramos da atividade humana; a facilidade dos intercâmbios materiais ou intelectuais impõe-se, pois, como necessidade de primeira ordem; além de que, o estabelecimento de um sistema racional de circulação torna-se um dos fatores mais poderosos da riqueza pública. (AGACHE,op.cit,p.133) 
Da mesma forma são evidenciados nas suas propostas fortes traços do movimento City Beautiful, cujo o exemplo mais significativo, é o plano de Burnham para a cidade de Chicago em 1909. Como já dissemos, as características desse movimento são a ancestralidade clássica e suntuosidade arquitetônica, expressas pelo tamanho majestoso dos prédios públicos e pela composição dos centros cívicos. Assim como no Plano de Avenidas encontramos no Plano de Remodelação para a cidade do Rio de Janeiro a mesma frase de Daniel Burnham para explicar o planejamento: "Make no Little Plans".(AGACHE,1926,p.19) Importa lembrar que foi Agache o primeiro professor, na França de um curso regular de urbanismo, em 1914, na Escola Livre de Ciências Sociais. Nesse curso, os aspectos gerais dos problemas urbanos eram apresentados em cinco secções, estudadas em quatro semestres e compreendendo cada uma um curso fundamental e uma série de conferências para aprofundar estudo de determinadas questões mais importantes.

Em seu artigo "Um grande urbanista francez Donat- Alfred Agache", o engenheiro - arquiteto Luiz de Anhaia Mello apresenta os principais itens tratados nas cinco conferências:

A primeira secção é dedicada aos estudos das origens e evolução das cidades, cujo conhecimento é à base do urbanismo. É no passado que se devem procurar as razões do presente e as previsões para o futuro. A segunda secção é destinada á organisação social das cidades, ao estudo das populações urbanas, suas necessidades e suas crises. Estuda as condições em que se exerce a acção social, seja preventiva ou curativa; examina as differentes medidas de ordem economica, de ordem sanitaria e de acção cultural. A terceira secção é destinada á organisação administrativa das cidades e ao estudo dos problemas políticos e administrativos que surgem da agglomeração da população em determinados pontos do território. As conferencias referem-se á organisação dos serviços públicos e ás questões actuaes relativas á administração das grandes capitaes. A organisação economica das classes é o objeto da quarta secção. Ahi são estudados os problemas relativos á utilisação irracional do solo, ás consequencias do desenvolvimento industrial moderno, ás causas da extensão centrífuga das cidades, o exagero da renda immobiliaria e tambem as cidades jardins e respectiva organisação social administrativa. O municipalismo ou a actividade municipal em materia industrial e commercial é estudado em detalhe nas 
conferencias do curso. Finalmente, a quinta secção é destinada á arte e technica da construção da cidade.[...].(MELLO,1928,PP.77-78)

Todas as semelhanças até aqui apontadas entre Agache e Prestes Maia reforçam o intercâmbio de conhecimentos bem como a prática da intervenção urbana na época da formação profissional do urbanista paulista. Nesta ocasião os Congressos Nacionais e Internacionais sobre urbanismo permitiam e incentivavam o intercâmbio de experiências e conhecimentos entre os vários países. O professor Benedito Lima de Toledo nos ajuda a fazer um percurso entre os principais Congressos realizados em diferentes cidades Européias. Entre eles, o Congrès Internacional de L'Art Public, realizado em Bruxelas, em 1898, os congressos dedicados especificamente ao Planejamento, como, a exposição em Dresden, em 1903, além dos congressos internacionais, em 1910, realizados em Berlim, Leipzig e Londres. (TOLEDO, 1996,p.259). Revela ainda que, em 1910, reuniram-se em Londres na "Town Planning Exhibition and Conference", os maiores expoentes em questões urbanas da época como Joseph Stübben, Patrick Geddes, Thomas Adams, Eugéne Hénard, Ebenezer Howard, Daniel Burnham e Raymond Unwin. Sabemos que estes profissionais discutiam soluções para o desenvolvimento das cidades calcadas em diferentes práticas teóricas. Nas apresentações de Geddes a pesquisa sociológica recebe um tratamento especial no planejamento urbano.

Depois dessa pesquisa geral sobre o ambiente geográfico e histórico, a pesquisa sociológica propriamente dita nos fornecerá elementos para elaborar uma literatura complementar. Sua substância estatística será procurada nos relatórios parlamentares e municipais e nos periódicos dedicados à economia. Mas serão necessárias pesquisas de primeira mão, detalhadas. Será necessário um relatório completo e bem ordenado da situação presente da população, que especifique suas ocupações, salários, orçamentos familiares, nível cultural, etc. (CHOAY,1979,p.273)

Geddes na verdade procurava estes caminhos como forma de evitar aproximações com os ideais utópicos; no seu entender a maioria dos planos apresentava modelos que eram aplicados em qualquer cidade. Para Geddes o passado e a história definem as características particulares de cada cidade; neste sentido a adaptação da pesquisa sociológica ao verdadeiro serviço social não seria uma idéia abstrata, mas um método aplicável. Suas idéias influenciaram o trabalho 
de seus contemporâneos Raymond Unwin e Barry Parker, defensores das novas cidades industriais.

As idéias de Geddes e Unwin eram diferentes das demais propostas urbanísticas da época, na Conferência realizada em Londres em 1910, Sir Patrick Abercrombie assim procurou assinalar a importância e a abrangência dos trabalhos de Geddes.

Houve um tempo em que parecia ser apenas necessário misturar numa garrafa o plano de extensão de cidades alemãs, o bulevar parisiense, a cidade - jardim inglesa e o centro cívico e 'park system' americanos para produzir uma mistura mecânica que poderia ser aplicada indiscriminadamente e beneficamente em qualquer cidade deste país, na esperança de que estivesse, dessa forma, planejada, de acordo com as mais atualizadas noções. Doce ilusão! ${ }^{12}$

$\mathrm{Na}$ perspectiva de Abercrombier podemos afirmar que o Plano de Avenidas expressa essa tendência eclética ao apresentar soluções extraídas das diversas cidades européias e norte-americanas. Mas difere dos preceitos de Geddes e Unwin com relação à pesquisa sociológica, a intenção de Prestes Maia ao discutir experiências realizadas em cidades constituídas, além de possibilitar o contraponto com a cidade São Paulo, procura incorporar em suas propostas apenas os aspectos aplicados e comprovados em diversas cidades.(MAIA,1930)

Ao enfatizar as vantagens oferecidas pela técnica e pelas novas soluções apresentadas pelo urbanismo, Prestes Maia justificava o caráter onipotente, visionário e formador do Plano ao lado da função autoritária do urbanista dizendo:

O plano fornece o rumo: a communidade seguil-o-á até onde puder ou quizer. Salvo auxiliar o trabalho de interpretação, selecção e adaptação, ahi finda a incumbência do urbanista. (MAIA,op.cit,p.x)

Apesar das distintas posturas que marcaram as definições de urbanismo e a função do urbanista entre esses profissionais, dentre elas, a visão diferenciada de Agache com relação à necessidade de uma equipe multidisciplinar no processo de elaboração de um Plano diretor frente à postura centralizadora de Prestes Maia com

\footnotetext{
12 Apud TRWHITT, J. Introduction. In Geddes, P. Cities in evolution. p. Xii citado por Toledo, Benedito Lima de, op. cit., p.260. URBANA, V.5, n० 7, out.2013 - Dossiê: Urbanistas e Urbanismo: a escrita da história... - CIEC/UNICAMP
} 
relação o papel do urbanista.É impossível não destacar a semelhança quanto à formação do campo conceitual do urbanismo presente em cada um desses urbanistas. Trata-se de justificar o poder de intervenção no meio urbano, ao recuperar os pressupostos teóricos que regeram a Teoria Médica do meio ambiente, desencadeada a partir da metade do século XIX. Tais princípios estão calcados no pressuposto da influência do meio ambiente na formação do caráter dos indivíduos. O artigo de François Béguin "As maquinarias inglesas do conforto" demonstra a partir de várias experiências que ocorreram na Europa no início do século XIX, como o habitat se transforma como espaço técnico e político de intervenção no meio urbano.(BÉGUIN,1991) O mesmo autor aponta algumas experiências realizadas na Inglaterra e Escócia durante o séc. XVIII. As chamadas "Vilas Modelos" foram construídas por proprietários, agricultores e industriais que fixaram os seus trabalhadores, oferecendo a eles todos os recursos necessários para sobreviver, isto é, moradias, escolas, farmácias e hospitais. Cuidavam, além disso, da educação dos filhos e criaram ainda um Instituto para a formação do caráter dos trabalhadores. Essas "Experiências" de vilas modelos foram conhecidas e avaliadas através das grandes enquetes realizadas na Inglaterra, com o intuito de confirmar a necessidade de intervenção no meio ambiente da população pobre.

Esses pressupostos teóricos estavam também presente, no ano de 1931 em São Paulo, nos debates do Primeiro Congresso de Habitação. Um evento promovido pelo Instituto de Engenharia em São Paulo, e pela prefeitura Municipal de São Paulo, que tinha como intuito, procurar viabilizar a construção para a população de baixarenda. Nesse evento os engenheiros-arquitetos demonstravam em seus discursos a importância da habitação como espaço de moralização do trabalhador nacional. ${ }^{13}$

Embora imbuído do mesmo campo conceitual presente nas teorias urbanísticas, Prestes Maia difere dos seus contemporâneos quanto à forma de atuação do urbanista. Ele elegia a técnica e os ensinamentos do urbanismo como condições necessárias para implantar o seu Plano Urbanístico. Em seus argumentos, os ensinamentos de todo movimento mundial de urbanismo dos últimos tempos, impediria os passos em falso a que outras cidades escaparam. A sua escala de trabalho como urbanista, sem dúvida, era a cidade, particularmente a preocupação em discutir os recursos necessários para implementar o sistema viário deixava para outros profissionais os estudos da escala humana, ou seja, dos problemas sociais,

\footnotetext{
${ }^{13}$ Tais discussões encontramos em Carpintéro, Marisa Varanda Teixeira, $A$ construção de um sonho - Os engenheiros-arquitetos e a formulação da política habitacional no Brasil, Campinas, UNICAMP, 1997.I URBANA, V.5, no 7, out.2013 - Dossiê: Urbanistas e Urbanismo: a escrita da história... - CIEC/UNICAMP
} 
culturais, políticos e econômicos. Assim como a forma de participação e de integração de outros profissionais na elaboração e na execução do Plano, preservando os conhecimentos específicos da engenharia e da arquitetura.Por outro lado um aspecto interessante da trajetória de Agache e de Prestes Maia é o fato que ambos trabalharam a serviço do Estado Novo. ${ }^{14}$

\section{O artista}

Além de procurar apresentar o domínio das técnicas urbanísticas em seus estudos, Prestes Maia logo no início do Plano de Avenidas, justifica a presença dos seus desenhos, dizendo:

Nos desenhos não nos preoccupamos com estylos architectonicos, pois urbanismo só interessam os effeitos de massa e as disposições geraes. Elles revelam, não obstante, infinitas possibilidades estheticas, que os engenheiros habitualmente esquecem e as cidades desperdiçam." (MAIA,op.cit,p.IX)

Chamo atenção para o procedimento cauteloso de Prestes Maia em minimizar no Plano a opção pelos estilos arquitetônicos. É certo que este, ao optar pelos estilos clássicos em suas aquarelas, não desconhecia a presença dos outros estilos arquitetônicos que estavam florescendo em várias cidades. Em São Paulo, entre os anos de 1920 e 1930, os estilos art déco e o modernismo, em especial, a Casa Modernista, da Rua Santa Cruz, de autoria do arquiteto, (de origem russa Gregori Warchavchik), projetada em 1927 e construída em 1928, já havia provocado polêmicas entre os engenheiros-arquitetos dentro e fora da academia. Distante dessa polêmica Prestes Maia encontra no desenho um instrumento de trabalho e de divulgação de suas idéias. Cabe lembrar que de 1927 a 1938, esse urbanista foi professor de desenho de perspectiva e arquitetônico da Escola Politécnica de São Paulo. Segundo o arquiteto Benedito Lima de Toledo;

Prestes Maia não fazia aquarelas apenas para exercitar um dom estético, ele tinha um poder extraordinário de fazer com que fossem antevistos seus planos através de uma perspectiva aquarelada.(TOLEDO,1996,p.62)

\footnotetext{
${ }^{14}$ Alfred Agache foi nomeado Conselheiro do Urbanismo, em 1939, por Getúlio Vargas e Francisco Prestes Maia prefeito interventor da cidade de São Paulo (1938-1945)

URBANA, V.5, no 7, out.2013 - Dossiê: Urbanistas e Urbanismo: a escrita da história... - CIEC/UNICAMP
} 
É exatamente no entrecruzamento da imaginação, das paixões através da arte e da razão que encontramos a sua concepção de metrópole. Uma metrópole construída de múltiplas imagens, que sempre parecem romper com o tempo; ousar na criatividade das composições como forma de legitimar as intervenções. Na aquarela, a imaginação identifica-se com a busca da antevisão das imagens em que as formas têm um rigor e a atração se faz na intimidade dos tons.

Pouco a pouco o cenário parece convidar o leitor a penetrar no espaço projetado que passa a funcionar como uma linguagem acessível e sedutora. A primeira imagem que o leitor encontra na introdução do "Plano de Avenidas" , é um quadro composto por dois homens semi nus e mulheres com vestimentas clássicas contornando o brasão de São Paulo, destacando a seguinte frase em latim, " Non Ducor Duco" ( Não sou Conduzido, Conduzo).

A segunda, é uma planta acanhada da cidade São Paulo de 1811 contendo os principais edificios centrais e em seguida o quadro de Oscar Pereira da Silva reproduzindo a primeira missa dos jesuítas na fundação da cidade. As próximas imagens são uma sequência de fotos em diferentes ângulos focalizando as edificações do Valle do Anhangabaú, como, o Viaduto do chá, predio Mackensie, Teatro Municipal, Hotel Esplanada, predio Martinelli, Automovel Club, Club Comercial e o predio Sampaio Moreira . Nessa sequência de fotos o autor chama atenção do leitor, atraves das legendas inseridas em cada foto, ressaltando que no decorrer de 40 anos esse local não sofreu nenhuma transformação .

Todas essas imagens conduz o leitor a sua primeira aquarela que é o projeto de remodelação do Vale do Anhagabaú, ou como ele definiu em seu Plano a "sala de visitas de São Paulo". Nessa aquarela são muitos aspectos a serem destacados; primeiramente o detalhe paisagistico com árvores e arbustos distribuídos de forma geométrica e compondo um magestoso cenário com o Viaduto do Chá. Entretanto, o Viaduto é o destaque principal desse quadro, a sua configuração lembra uma ponte sobre o Rio Sena potencializando nessa linguagem arquitetônica o dialogo com as edificações existentes. É interessante notar que no desenho artístico a perspectiva pode ser definida como um recurso gráfico que utiliza o efeito visual de linhas convergentes para criar a ilusão de tridimensionalidade do espaço e das formas.E nesse quadro Prestes Maia, explora essa técnica para apresentar lá ao fundo do Vale o projeto do novo Paço Municipal. 
Consciente do sentido artístico e sedutor de suas aquarelas diz o urbanista: " o plano é apenas o verso, a estampa, onde o lápis muita vez phantasia e o aquarellista compõe maravilhas que irão engrossar edições futuras do conhecido Poten." (MAIA,op.cit,P.4)

A linguagem monumental e eclética com elementos do clássico é aplicada nas pontes, pórticos, viadutos, monumentos esculturais ornados de arcos, colunas e abóbadas. A preferência cultural de Prestes Maia com relação à arquitetura clássica se estende para a literatura, em especial os clássicos como, Plínio Antigo, além das poesias de Lucrécio e Virgílio, segue a preferência para a música clássica, óperas e as operetas. Com certeza, mais adiante em 1938, ao assumir a prefeitura da cidade de São Paulo essa preferência se comprova em ações contrária ao projeto político e cultural implementado por Mário de Andrade e sua equipe junto ao Departamento de Cultura. ${ }^{15}$

Distante de toda programação cultural desencadeada pelo grupo de Mário de Andrade, o espaço da cultura no Plano de Avenidas estava representada na formação cívica através da propaganda como aconteceu com as experiências da "City Beautiful Movement" nas cidades norte-americanas. A idéia de "municipal art" era usar as cidades no patrocínio da arte.Como já disse, Prestes Maia comenta os trabalhos desenvolvidos, no ano de 1909, por Daniel Burham e Edward .H. Bennett no plano regulador de Chicago. Neste trabalho estes engenheiros procuram sobrepor a retícula uniforme da velha cidade a um sistema simétrico de novas ruas em diagonal, contendo um semi-círculo de quase $32 \mathrm{Km}$ de diâmetro. Estas medidas se colocavam como tentativa de solucionar os problemas de circulação, de zoneamento e da distribuição dos edifícios públicos. Importa ressaltar que entre as preocupações do plano de atender aos problemas de circulação, zoneamento e distribuição havia a proposta de " popularização" do Plano a partir de uma campanha preliminar com objetivo de conquistar a opinião pública. ${ }^{16}$ Além de Chicago, nesta mesma época

\footnotetext{
15 Mário de Andrade, Antônio Alcântara Machado, Paulo Duarte, Sérgio Milliet e outros foram os responsáveis pela criação do Departamento de Cultura no decorrer de (1935-1938). A preocupação do Departamento de Cultura era realizar uma série de atividades didáticas e culturais, incluindo todos os setores da sociedade e promovendo a partir da cultura a formação da cidadania. Paulo Duarte em seu livro "Mário de Andrade por ele mesmo", denuncia a atitude e o erro do Prefeito Prestes Maia quanto a substituição da programação musical da Divisão de Expansão Cultural.

O projeto era extremamente amplo envolvendo sociólogos, antropólogos, etnólogos, musicistas, que buscavam a troca e o conhecimento cultural nacional. Verificar os estudos de BARBATO, Roberto Júnior em seu livro Missionários de um Utopia Nacional Popular, São Paulo, FAPESP, Anablume, 2004.

${ }^{16}$ Consultar a tese de doutoramento, Carpintéro, Marisa V. Teixeira, Em busca da imagem : a cidade e o seu figurino (São Paulo1938-1954), defendida no Departamento de História/IFCH/UNICAMP, 1998, e os estudos de Sies, Mry Corbin and Silver Christopher, Planning the Twentieth-Century American City, Harrisonburg, Vírginia, The Hopkins University Press, 1996.
}

URBANA, V.5, no 7, out.2013 - Dossiê: Urbanistas e Urbanismo: a escrita da história... - CIEC/UNICAMP 
outras cidades norte-americanas, como Dallas, Texas, Cincinatti, também realizaram os trabalhos de propaganda do Plano da Cidade. Novamente chamo atenção para as aproximações entre Agache e Prestes Maia no tocante as questões que permeiam a arte e a técnica da construção da cidade e a necessidade da popularização do Plano.

Em São Paulo não será diferente, na opinião de Prestes Maia, mesmo após discutido e aprovado um projeto, vem a etapa mais difícil: será a dos obstáculos postos pela ausência de espírito cívico ou pela ambição do lucro. Neste sentido, ele propõe uma campanha na imprensa, nas associações, nas escolas, para que esse "espírito" se forme com o intuito de prestarem aos empreendimentos municipais o apoio que merecem. O autor enfatiza a importância da construção dos centros cívicos em locais estratégicos da cidade, como forma de manter a tradição e a história do desenvolvimento paulista atrelada à projeção de uma nova metrópole.

Nessa perspectiva ele propõe para a Ponte Grande, ligação do centro com a margem direita do Tietê, onde estariam à estação central, o aeroporto e o porto fluvial, as esculturas em homenagem às bandeiras. Do mesmo modo a condição simbólica da imagem aparece na proposta de transformar todo trecho do vale entre os viadutos Sta. Ephigenia e de S. Francisco numa só praça, ou melhor em um centro cívico, norteado de imponentes edifícios, dentre eles , o Paço Municipal.(MAIA,op.cit, p.5) A preocupação do autor era convencer os leitores e depois os eleitores da viabilidade das obras propostas e também de criticar os autores dos Planos Urbanísticos que ficaram apenas no papel. Segundo a sua opinião o Plano de Avenidas antecipa as dificuldades quando diz :

...representa um ideal cívico, inattingível como todos os ideaes, mas guia e diretriz na busca da perfeição, e actúa sobre a imaginação como a mais eficaz propaganda, mesmo porque é difícil a esta effetuar-se abstratamente, sem algo concreto que fale aos sentidos. (MAIA,op.cit,p.2)

Visto do ângulo político essas linguagens presente no Plano de Avenidas encontraram ressonância com o regime ditatorial do Estado Novo e ainda justificaram a escolha do urbanista Francisco Prestes Maia para ocupar o cargo de prefeito interventor de São Paulo (1938-1945).

\section{O discurso político do Urbanista}


Pode-se enganar todo o povo uma parte do tempo.

Pode-se enganar uma parte do povo todo o tempo.

Mas não se pode enganar todo o povo todo o tempo.

\section{Lincoln}

" Confesso que me surpreendeu a escolha feita pelo Sr. Ademar de Barros do meu nome para a Prefeitura de São Paulo", proferiu Prestes Maia no dia de sua posse como novo prefeito Municipal de São Paulo. ${ }^{17}$ Nesse parágrafo, o novo prefeito expressa que o motivo dessa escolha se deu em função do seu trabalho como urbanista. E ainda em sua posse o mesmo delineia a sua imagem como político dizendo:

[...] farei uma administração, única exclusivamente técnica, sem qualquer outras considerações. A parte política, de que sempre me mantive afastado, continuará ser alheia aos meus atos, como homem público. Aliás no regime vigente, a política depende, diretamente, dos meus superiores. (MAIA,1938)

Consciente do momento político, Prestes Maia construía em seu discurso o perfil adequado para a política vigente, assim como para Getúlio Vargas o discurso técnico e racional do urbanista simbolizava a imagem propagandística da cidade de São Paulo no Estado Novo. Imagem que procurou apresentar no livro " Brasil 1938" editado pela Câmara do Comércio Franco - Brasileira de Paris, com o intuito divulgar a imagem da política brasileira na França. ${ }^{18}$ Após uma síntese das premissas políticas do Estado Novo ao lado do Programa de Governo, cada capital brasileira apresentou através de seus prefeitos e autoridades, as principais características políticas, econômicas e sociais, acompanhado de diagnósticos e de futuras projeções para as respectivas cidades. A cidade de São Paulo foi representada pelo seu prefeito Francisco Prestes Maia, que a qualificou como o maior centro industrial e comercial da América Latina. Após apresentar alguns dados financeiros e imagens de monumentos e edifícios, dentre eles, o Museu Ypiranga,o prédio do Correio e Telégrafo, o edifício Martinelli, a Escola Normal, e outros, o prefeito anunciou os problemas atuais da cidade e a solução encontrada a partir da implantação do Plano de Avenidas.

\footnotetext{
${ }^{17}$ Discurso de posse do prefeito Francisco Prestes Maia in Revista do Arquivo Municipal, São Paulo, Departamento de Cultura, ano IV, volume XLVII, 1938.

${ }^{18}$ Brasil 1938, Edite par La Chambre de Commerce Franco Bresilienne de Paris, organisé sous M. Mario de Albuquerque Pimentel, 1938.

URBANA, V.5, n 7, out.2013 - Dossiê: Urbanistas e Urbanismo: a escrita da história... - CIEC/UNICAMP
} 
Como prefeito, procurou realizar grande parte das propostas viárias contidas no Plano de Avenidas. Na sua primeira gestão de 9 de março de 1938 à 10 de novembro de 1945, administrou com absoluta liberdade de ação, ou seja, sem a Câmara Municipal e sem o Tribunal de Contas, instituições abolidas pelo Estado Novo. Todas as obras realizadas nesse período foram divulgadas em seu livro intitulado "Os Melhoramentos de São Paulo".(MAIA, 1945)

Neste livro que foi o relatório de sua gestão, Prestes Maia escreveu uma pequena introdução esclarecendo as dificuldades financeiras encontradas e comentando de forma sintética as intervenções realizadas. Enfatizo nesse documento três aspectos importantes que refletem a imagem que ele procurou construir. $O$ primeiro aspecto foi se colocar não apenas como técnico ou teórico do urbanismo, mas também, como administrador. Nas primeiras páginas do livro de Melhoramentos de São Paulo, ele se desculpa pelo "pecado de mocidade cometido ao elaborar à dez anos atrás um "Plano" sem imaginar um dia poder executar.

"Pecado de mocidade e justa atrapalhação a quem, ao compor para os outros, nunca imaginara ver-se um dia na contingência de executar. "(MAIA,1945,p.1)

O segundo aspecto interessante é o relato das dificuldades financeiras enfrentadas no início de sua gestão. O prefeito ressalta, a sua política administrativa preocupada e cautelosa com o dinheiro público e ainda divulga os resultados orçamentários positivos alcançados pela sua administração. Nesse relato salienta que:

Sem corte de funcionalismo nem vencimentos, sem aumento de tributos, apenas reduzindo á tentadora criação de cargos e repartições, congelando certas despesas e deixando exercer-se o crescimento natural da receita, adotando a norma dos orçamentos cautelosos e dos créditos especiais para as obras maiores, baseados em saldos efetivamente verificados, logo conseguimos um superávit orçamentário... (MAIA,1945,p.1)

Trata-se, sem dúvida, de um texto político, pois Prestes Maia deixou de relatar os conflitos na contenção dos gastos referente aos projetos desenvolvidos pelo Departamento de Cultura. Também não menciona o Ato n. 1407, de 16 de maio de 
1938, que suprimiu vários cargos do quadro do funcionalismo municipal do Departamento de Cultura. ${ }^{19}$

O terceiro aspecto são as inúmeras fotos que o qualificou como " mestre de obras", apresentando a abertura e o alargamento das ruas e avenidas, a instalação dos equipamentos urbanos, a canalização do rio Tietê, a construção de pontes, do Estádio Municipal, da Biblioteca Municipal e dos Parques Infantis. Paulo Duarte enfatiza que algumas dessas obras já haviam sido iniciadas na gestão anterior do prefeito Fábio Prado, dentre elas, o Estádio Municipal, a Biblioteca Municipal, a Avenida 9 de julho e uma série de Parques Infantis. Todavia, para a indignação desse escritor, essas obras foram inauguradas com a participação do presidente Getúlio Vargas como propaganda do Estado Novo.

Solenidades importantes a fim de que o público visse bem as benemerências getulistas. Inaugurou-se no mesmo dia em que a Ponte das Bandeiras. Era a glória paulista também acarinhada pelo Estado Novo. Houve discurseira, lá à beira do Tietê, houve discurseira, à beira do casco da Biblioteca. Evidentemente, nem palavra sobre os verdadeiros criadores do Instituto. ${ }^{20}$.(DUARTE, 1977, p.78)

As palavras acima de Paulo Duarte não abalaram as imagens por ele construídas ao longo de sua trajetória política. Nem tão pouco o abandono de algumas ideias presente ao longo de sua trajetória como urbanista e presidente da Sociedade Amigos da Cidade, dentre elas, a sua opinião em favor da formação das Comissões de Urbanismo. Como já mencionei anteriormente, em 1934 , como presidente da Sociedade Amigos da Cidade, Prestes Maia articula com outros urbanistas, dentre eles Luis de Anhaia Mello, a formação da Sociedade Amigos da Cidade, entidade civil que se propunha a apontar soluções para os problemas da cidade e lutar para a elaboração do Plano Geral da Cidade e pela formação de uma Comissão do Plano da Cidade. Após a sua primeira experiência como prefeito interventor da capital(19381945), o urbanista contrário a postura inicial, salienta as inúmeras dificuldades na composição da Comissão do Plano da Cidade, dentre elas, a escolha dos representantes e os interesses diversos. ${ }^{21}$

\footnotetext{
${ }^{19}$ Ato no 1407 , de 16 de maio de 1938 , Suprime cargos vagos do funcionalismo municipal in Revista do Arquivo Municipal, Departamento de Cultura, op. cit, p. 280.

${ }^{20}$ Duarte, Paulo, op.cit, p.78

21 "Uns são meros 'medalhões', outros entram só por prestigio social ou político; terceiros são heterogêneos, atrapalhativos ou exibicionistas. As indicações, quase sempre meramente protocolares, por sociedade cívicas ou técnicas nem sempre são mais felizes que as nomeações diretas" Veja : Maia, URBANA, V.5, no 7, out.2013 - Dossiê: Urbanistas e Urbanismo: a escrita da história... - CIEC/UNICAMP
} 
As imagens de urbanista, do técnico exemplar, do mestre de obras, do prefeito honesto, do prefeito apartidário."se mantém durante a sua primeira e segunda gestão. Essas imagens aparecem, no ano de 1961, nos slogans de sua campanha a prefeito de São Paulo.

$\mathrm{Na}$ capa do folheto de propaganda a prefeito, assim como no Plano de Avenidas, está o brasão de São Paulo ao lado da seguinte frase: " Prestes Maia - Fez, Prestes Maia - Fará". O texto é uma síntese descritiva do que foi realizado em sua primeira gestão salientando a capacidade técnica e administrativa e a honestidade do candidato.

Amigo: você que leu o que foi escrito, que conhece sua cidade, que acompanhou a passagem de mais de uma dúzia de Prefeitos depois de 1945, procure uma realização grandiosa de qualquer deles; compare com as de Prestes Maia, examine as qualidades dos atuais candidatos e, certamente concluirá resumindo:- $O$ passado e o presente de Prestes Maia garantem a futura administração da cidade de São Paulo "22

É curioso porque as características acima assinaladas em sua campanha política, também encontram ressonância com outro momento político marcado pelos partidos populistas. Durante sua trajetória política, Prestes Maia ora se apresentava como técnico, ora como morador apaixonado pela cidade. É claro que esta era a sua forma de fazer política, que podemos interpretar a partir dos artigos escritos, no ano de 1954, em uma coluna diária no jornal Última Hora. Nestes artigos, encontramos o esforço em se comunicar com a população a partir da escolha de temas variados apresentados com um vocabulário claro e bem escrito para que todo leitor pudesse acompanhar, refletir e, ao mesmo tempo se convencer dos argumentos por ele apresentados.

Nesta, coluna o engenheiro procurou esclarecer a população sobre os projetos que vinham sendo apresentados pelas autoridades públicas. Esta era a sua forma de fazer política, criticava os projetos usando para isso todo o conhecimento técnico e afastava-se dos costumeiros ataques que os políticos procuravam fazer aos seus adversários. Outra característica importante do seu texto é o lado populista, marcado pela preocupação em se expressar como habitante comum da cidade. O habitante

Francisco Prestes, Os grandes problemas urbanísticos de São Paulo in Digesto Economico, maio de 1953, p. 54

22 Panfleto de campanha de Francisco Prestes Maia, publicado em 1961- Acervo da Biblioteca Francisco Prestes Maia.

URBANA, V.5, no 7, out.2013 - Dossiê: Urbanistas e Urbanismo: a escrita da história... - CIEC/UNICAMP 
preocupado com a falta de água, racionamento de energias, nomenclatura das ruas, vistorias dos teatros, traçados das ruas, além dos problemas específicos do dia a dia de um bairro.

Confirmo a força da imagem política de Prestes Maia ao me deparar, com seu arquivo pessoal, em que encontrei uma série de cartas, telegramas e abaixo-assinado escrito por moradores, entidades de bairro, comerciantes e admiradores em apoio a sua candidatura a prefeito. $^{23}$ Entre essa documentação constatei também uma entrevista de Prestes Maia, no ano de 1961, concedida ao jornal Estado de São Paulo relatando as dificuldades enfrentadas no decorrer de um ano de administração. Neste depoimento é possível perceber o momento conflituoso de sua gestão, pois os políticos adversários e a imprensa acusavam a sua ausência e o abandono da cidade. Em respostas as acusações Prestes Maia, diferente dos discursos técnicos que marcaram os momentos anteriores de sua trajetória, evoca a necessidade da moralização administrativa. Além de criticar os políticos desonestos e o déficit da prefeitura deixado pelo seu antecessor Adhemar de Barros, acusa a injusta discriminação de rendas entre município, Estado e prefeitura, estabelecida pela Constituição de $1946 .^{24}$ Sendo assim, empreende uma campanha procurando mobilizar outros e estados e municípios, para alterar o artigo 20 da Constituição que excluía as capitais dos Estados da restituição de 30\%sobre o excesso da arrecadação do Estado sobre os municípios. Interessante, que no final da entrevista o urbanista apresenta aos leitores, uma outra linguagem, são gráficos e números que procuram demonstrar o seu estudo sobre a distribuição da receita tributária federal, estadual e municipal no município da capital de São Paulo.Entendo que essa seria mais uma imagem a ser explorada: as questões municipalistas.

A recente reedição do livro "Os melhoramentos de São Paulo" organizado pela sua filha Adriana Prestes Maia Fernandes, traz uma série de depoimentos proferidos, no ano de 1996, no transcorrer das comemorações do centenário do nascimento de Prestes Maia. São depoimentos de amigos, admiradores e estudiosos de sua obra, que reiteram incansavelmente todas as imagens aqui expostas. Entre essas imagens seus

${ }^{23}$ Entre as inúmeras cartas transcrevo as entusiásticas palavras do eleitor Sr. José Marcondes de Lima (10/02/1961) " Venho trazer a V.sa os meus entusiásticos aplausos pela sua candidatura à Prefeitura de São Paulo, já referendada por dois grandes partidos, que terão a seguí-los, não tenho dúvidas, pelo P.D.C e pelo P.R, que são embuídos de espírito público, como já demonstraram em mais de uma oportunidade."

\footnotetext{
${ }^{24}$ O município ficava com menos de $1 / 6$ dos impostos arrecadados na cidade-residia a impossibilidade financeira da realização das obras por ele planejadas.

URBANA, V.5, n 7, out.2013 - Dossiê: Urbanistas e Urbanismo: a escrita da história... - CIEC/UNICAMP
} 
amigos reescrevem a autodefinição de político presente no início do seu livro "Os melhoramentos de São Paulo". 25 :

Não pertenço e nem pertenci a qualquer partido por um tanto cético e avesso pessoalmente à disciplina, sem desconhecer, entretanto, a necessidade do regime partidário... Embora, pelas raízes de família, relacionado com os partidos aproximando-se doutrinariamente do trabalhismo. Sou político, embora não político partidário... A partidário, mas não apolítico.(MAIA,2010,p.220)

Investigar as diferentes linguagens presente no discurso urbanístico e político de Prestes Maia nos coloca o desafio de conhecer os seus interlocutores e perseguir a formação do campo de saber do urbanismo.Permite ainda caminhar nos espaços da sensibilidade e reconhecer em cada percurso como as tensões entre o vivido e o desejado são fundamentais para se olhar o outro e conhecer as tramas que permeiam a história e as diversas formas de linguagens na política

\section{Referências}

AGACHE, Alfred. Cidade do Rio de Janeiro - Extensao e Embelezamento.

Organizações projectadas pela administração de Antonio Prado Jr. AMD. P>L>GS.F>U, Foyer Brésilien, 1926.

ANSART, Pierre, "La gestion des passions politiques, L' Age d' Homme, Lausanne, 1998

BARBATO, Roberto Júnior. Missionários de uma Utopia Nacional Popular, São Paulo: Fapesp; Annablume, 2004.

BÉGIN, François. As maquinarias inglesas do conforto. Espaço e Debates, CIDADE, no 34, Ano XI, 1991.

BERNARD, Lepetit. Por uma nova história urbana. Coleção de textos organizada por. Heliana Angotti Salgueiro. Trad. São Paulo: Edusp, 2001.

BORGES, Vavy Pacheco. O eu e o outro na Relação Biográfica. In: NAXARA, Marcia, MARSON, Izabel \& BREPOHL, Marion. (orgs.) Figurações do Outro. Uberlândia:

Edufu, 2009, p.225-238

\footnotetext{
${ }^{25}$ Dessa vez, V.Exa vai à Prefeitura de S. Paulo pelos hombros do povo, quer queiram os partidos quer não queiram.[...] São Paulo de alguém como vossa Exa. Guarda fiel dos dinheiros públicos, sentinela avançada da virtude de nossos maiores, daqueles que um fio de barba valia como documento. Eleitor de vossa Exa.em todos os pleitos eleitorais, se Deus quizer, irei depositar o meu voto em seu honrado e impoluto nome [...]Carta de um admirador Sr. José Marcondes de Lima (10/02/1961) - Arquivo encontrado na Biblioteca Francisco Prestes Maia.
}

URBANA, V.5, no 7, out.2013 - Dossiê: Urbanistas e Urbanismo: a escrita da história... - CIEC/UNICAMP 
BOURDIEU, Pierre. (1994) Razões Práticas sobre a teoria da ação. Trad. Marisa Corrêa. Campinas-SP: Papirus, 1996.

BRUAND, Catheriene Donald Alfred Agache:urbanismo, uma sociologia aplicada in Cidade, Povo e Nação Gênese do urbanismo moderno, Org.RIBEIRo Luiz Cesar de Queiroz e PECHMAN Robert, Rio de Janeiro , Civilização Brasileira, 1996.

CAMPOS, Candido Malta. Os rumos da cidade. Urbanismo e modernização em São Paulo. São Paulo: SENAC, 2000.

CARPINTÉRO, Marisa V. Teixeira. Em busca da imagem: a cidade e o seu figurino (São Paulo, 1938-1954). Tese de doutorado, 1998, IFCH/UNICAMP.

CARPINTÉRO, Marisa, "Linguagens políticas na trajetória do engenheiro-arquiteto Francisco Prestes Maia" publicado no livro org. SEIXAS,Jacy,CERASOLI,Josianne e NAXARA, Márcia, Tramas do Político :Linguagens, Formas,Jogos, Urbelândia,EDUFU, 2012.

CARPINTÉRO, Marisa Varanda Teixeira. A construção de um sonho - Os engenheiros-arquitetos e a formulação da política habitacional no Brasil. Campinas: Ed.Unicamp, 1997.

CINTRA,João Florence d' Ulhôa \& MAIA, Francisco Prestes. Um problema actual; os grandes melhoramentos de São Paulo, Boletim do Instituto de Engenharia, São Paulo, vol VI, no 29, 1924

CHOAY,Françoise.(1965). O urbanismo,São Paulo,Perspectiva ,1979.

DUARTE, Paulo. Mário de Andrade por ele mesmo. São Paulo: Co-edição Hucitec/ Secretaria da Cultura, Ciência e Tecnologia do Estado de São Paulo, 1977.

FARIA, Rodrigo, Biografia, não mais Trajetória: para (re)pensar argumentos de outrora,Posfácio do Livro São Paulo, O Urbanista e a Cidade, José de Oliveira Reis e o Rio de Janeiro - uma biografia profissional, . Editora Alameda/FAPESP,2011 FELDMAN, Sarah. Planejamento e Zoneamento em São Paulo, 1947-1972. São Paulo:EDUSP,2005.

FERNANDES, Adriana Prestes Maia. Os Melhoramentos de São Paulo, de Francisco Prestes Maia. São Paulo: Imprensa Oficial, 2010,

GINZBURG, Carlo.(1976) O queijo e os vermes. O cotidiano e as ideias de um moleiro perseguido pela Inquisição.Tradução Maria Betânia Amoroso, São Paulo: Companhia das Letras, 1997.

GROSTEIN, Marta Dora, A cidade clandestina: Os mitos e os ritos (1900-1987). São Paulo, Tese de doutorado, 1990, FAU-USP.

LEME, Maria Cristina da Silva. Revisão do Plano de Avenidas: Um estudo sobre o Planejamento Urbano em São Paulo. Tese de doutorado, FAU/USP, 1990. 
MAIA, Francisco Prestes. Introducção ao Estudo de Um Plano de Avenidas para a cidade de São Paulo. São Paulo: Melhoramentos, 1930.

MAIA, Francisco Prestes.Um ano de administração - entrevista pelo prefeito Francisco Prestes Maia,jornal Estado de São Paulo, 23 de abril de 1962.

MAIA, Francisco Prestes. Os Melhoramentos de São Paulo. São Paulo: Sub-divisão Gráfica da Prefeitura do Município de São Paulo, 1945.

MELLO, Anhaia Luis. Urbanismo e suas normas para organização de planos. Revista do Instituto de Engenharia. São Paulo, vol. VII, no 89, abril de 1933.

MELLO, Anhaia Luis.Um grande urbanista francez, Donald-Alfred Agache ,Revista Polytecnica, São Paulo, AnoXXV, maio-julho, números 85-86, 1928 MEYER, Regina Prosperi. Metrópole e Urbanismo: São Paulo 1950. Tese de doutorado, 1991, FAU-USP.

PIMENTEL, M. Mario de Albuquerque Brasil 1938. Edité par La Chambre de Commerce Franco Bresilienne de Paris, 1938.

Revista do Arquivo Municipal, São Paulo, Departamento de Cultura, ano IV, vol.XLVII, 1938.

ROLNIK, Raquel. A cidade e a Lei: Legislação, política e territórios na cidade de São Paulo. São Paulo: Studio Nobel, 1997.

SEGAWA, Hugo. Arquiteturas no Brasil. São Paulo: Edusp, 1997.

SEGAWA, Hugo. Prelúdio da Metrópole: Arquitetura e Urbanismo em São Paulo na passagem do século XIX ao XX. São Paulo: Ateliê Ed., 2000.

SIES, Mry Corbin \& SILVER Christopher. Planning the Twentieth-Century American City. Harrisonburg, Vírginia: The Hopkins University Press, 1996. SOMEK, Nadia. A cidade Vertical e o urbanismo Modernizador: São Paulo 1910-1939. São Paulo: Studio Nobel/FAPESP, 1996.

SOUZA, Maria Adélia Aparecida de. A Identidade da Metrópole. São Paulo: Hucitec, 1994.

STEVENSON, Carlos W. Conferência acêrca do urbanismo na cidade de Campinas. Campinas: Casa Genoud, 1934

TOLEDO, Benedito Lima. O mestre e o pincel. In: Revista Cidade. São Paulo:

Departamento do Patrimônio Histórico/Secretaria Municipal de Cultura, ano III, 1996. TOLEDO, Benedito Lima de. Prestes Maia e as origens do Urbanismo Moderno. 1996. 